\title{
Disseminated cutaneous atypical mycobacteriosis by M. chelonae after sclerotherapy of varicose veins in a immunocompetent patient: a case report ${ }^{*}$
}

\author{
Nathalia Dias Negrão Murback ${ }^{1}$ \\ Maurício Antônio Pompílio ${ }^{1}$ \\ Gunter Hans Filho ${ }^{1}$
}

\author{
Minoru German Higa Júnior ${ }^{1}$ \\ Eunice Stella Jardim Cury ${ }^{1}$ \\ Luiz Carlos Takita ${ }^{1}$
}

\begin{abstract}
A bstract: Atypical mycobacteria are saprophytic organisms not transmitted from person to person, which affect mainly immunosuppressed but also immunocompetent individuals. We present a case of atypical mycobacteriosis after a vascular procedure, with widespread cutaneous lesions associated with polyarthralgia. Mycobacterium chelonae was identified by the polymerase chain reaction (PCR) method. The patient showed improvement after treatment with three antibiotics. Mycobacterium chelonae causes skin lesions after invasive procedures. The clinical form depends on the immune state of the host and on the entry points. The diagnosis is based essentially on culture and the mycobacteria is identified by PCR. We highlight the importance of investigating atypical mycobacteriosis when faced with granulomatous lesions associated with a history of invasive procedures.
\end{abstract}

Keywords: Bloodless medical and surgical procedures; Diagnosis; Diagnostic services; Elective surgical procedures; History; Microbiology; Mycobacterium infections, nontuberculous; Epidemiology; Therapeutics

\section{INTRODUCTION}

Opportunistic mycobacteria - also called atypical or environmental mycobacteria - are referred to as non-tuberculous mycobacteria (NTM) and represent $10 \%$ of all mycobacterioses. ${ }^{1}$ They are saprophytic organisms not transmitted from person to person. ${ }^{2}$

NTM cause lung disease, lymphadenopathy, skin and soft tissue lesions. Since they are opportunistic pathogens, they affect immunosuppressed individuals. Moreover, the number of disseminated cases increased significantly over time. 2,3 Immunocompetent individuals are also affected, especially when undergoing invasive procedures. In these cases, they are usually restricted to the skin and underlying tissues.
1,3,4 The increasing number of cases is explained by the $\mathrm{HIV} / \mathrm{AIDS}$ pandemic associated with the high number of surgeries and cosmetic procedures performed with medical equipments not properly sterilized. ${ }^{5}$

About 50 NTM species are known and only a few of them are pathogenic for man. The species most commonly associated with skin diseases are: $M$. marinum, $M$. ulcerans, $M$. fortuitum, $M$. chelonae and $M$. abscessus. ${ }^{6}$

The diagnosis of cutaneous infection by NTM remains a challenge, especially in immunocompromised individuals, due to the large number of differential diagnoses. ${ }^{3}$

Approved by the Advisory Board and accepted for publication on 30.06.2014

Study conducted at the University Hospital Center - Federal University of Mato Grosso do Sul (NHU-UFMS) - Campo Grande (MS), Brazil. Financial Support: None.

Conflict of Interest: None.

1 Federal University of Mato Grosso do Sul (UFMS) - Campo Grande (MS), Brazil.

(C2015 by Anais Brasileiros de Dermatologia 
We present the first report in the literature of atypical mycobacteriosis by $\mathrm{M}$. chelonae after sclerotherapy of varicose veins. It is noteworthy that the cutaneous dissemination occurred in an immunocompetent patient.

\section{CASE REPORT}

A 57-year-old female patient reported the appearance of lumps in her left leg, followed by lesions on the forearms, wrists, thighs and the face, associated with polyarthralgia, especially in the knees and in the joints of both hands, with significant functional limitation. The patient had undergone sclerotherapy of varicose veins 40 days before the onset of symptoms.

Ectoscopic examination revealed erythematous vioulaceous, indurated and fistulized papules, nodules and plaques - some of which had sero-hematic crusts on the forearms, wrists and lower limbs, and in the left temporo-malar region. There was a slight joint swelling in the knees and joints of the hands (Figure 1).

Tuberculin test was non-reactive. Serology for infectious diseases and BAAR test were negative. Autoantibodies were non-reactive. Rheumatoid factor showed a slight increase (22 IU / ml). ESR of $44 \mathrm{~mm} /$ hour and CRP (C reactive protein) of 15.2. A punch biopsy of the facial lesion was performed. Bacterial culture revealed coagulase-negative Staphylococcus.
Fungal culture was negative. Positive AFB smear. A culture on Lowenstein-Jensen medium showed a growth of mycobacteria, identified by PCR with partial rpoB gene sequencing as Mycobacterium chelonae.

Histopathologic examination revealed granulomatous inflammation in the dermis, with multinucleated giant cells and areas of necrosis. Culture was negative for fungi and parasites. AFB smear was negative, as well as immunohistochemistry for Leishmania spp and mycobacteria (Figures 2 and 3).

Computed tomography was nonspecific. Bone scintigraphy showed radiotracer hyperconcentration in multiple joints (Figure 4).

After a sixth-month treatment with ciprofloxacin (400 mg twice daily IV) and clarithromycin (500 mg twice daily orally) and a two-month treatment with amikacin (1g/day IV),lesions healed, inflammatory markers normalized and arthralgias persisted with lower intensity.

\section{DISCUSSION}

M. chelonae is a rapidly growing mycobacteria (RGM) included in group IV of Runyon's classification and widely distributed in nature. It is found in the water, soil, in animals and bioaerosols, and even under supposedly adverse conditions, such as low $\mathrm{pH}$ and varying temperatures. It often causes skin lesions after
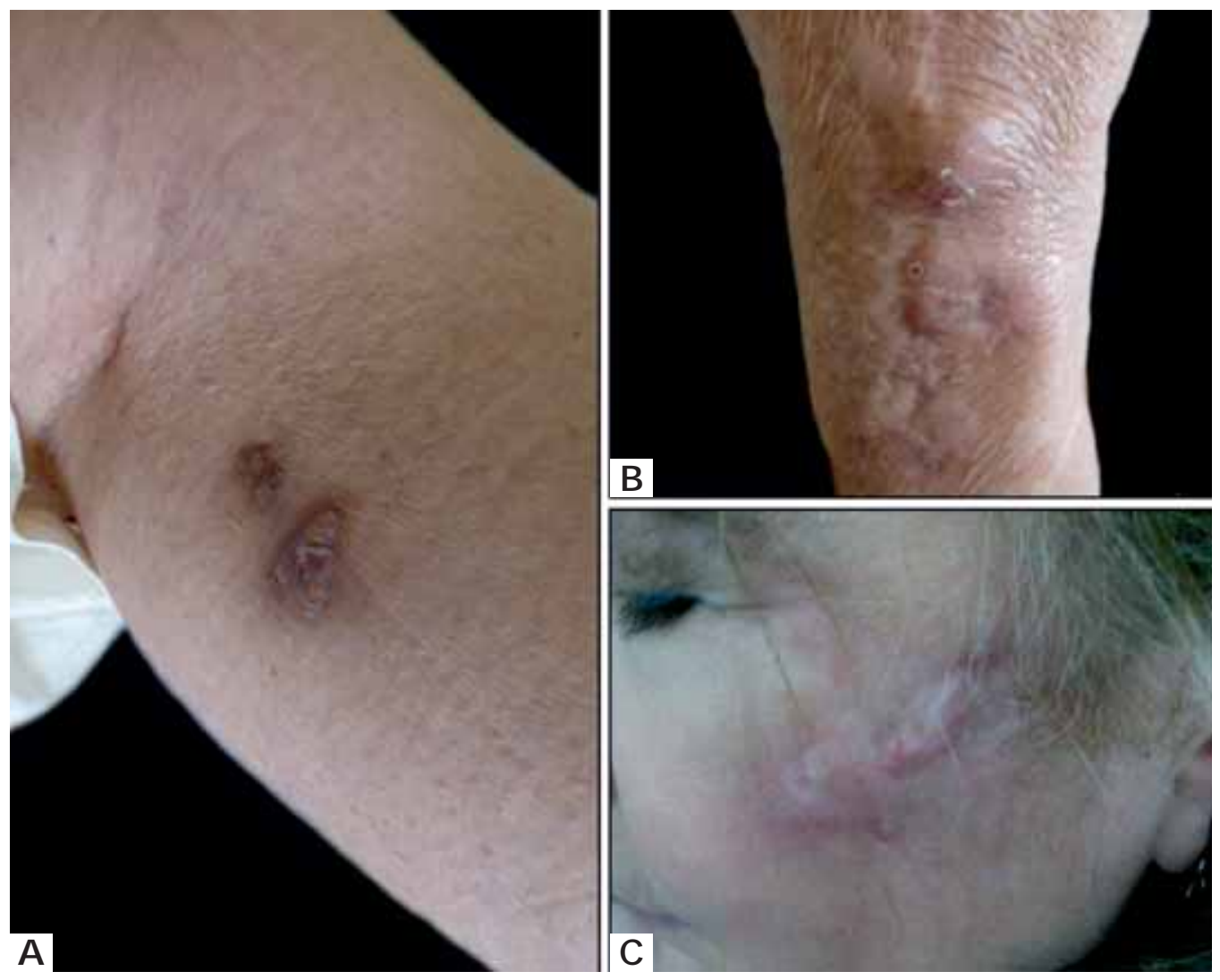

Figure 1:

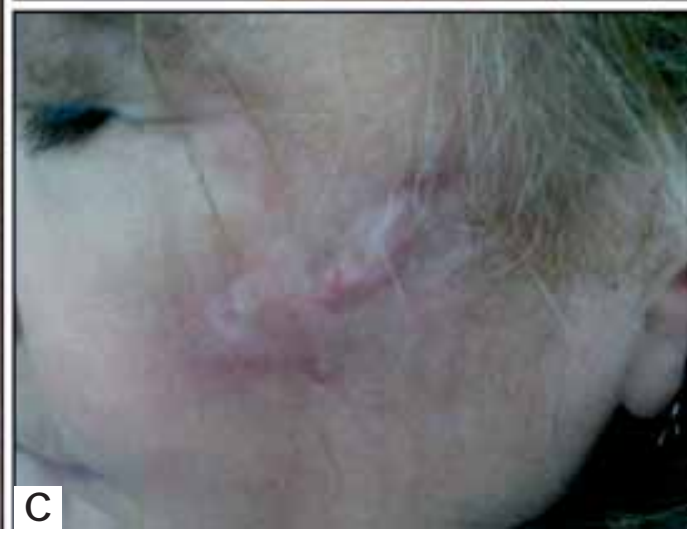

Cutaneous manifestations. Confluent, erythematous vioulaceous, indurated nodules and plaques - some of which were fistulized - in the posterior region of left leg (A), on the extensor surface of the wrist (B), and in the left temporo-malar region (C) 


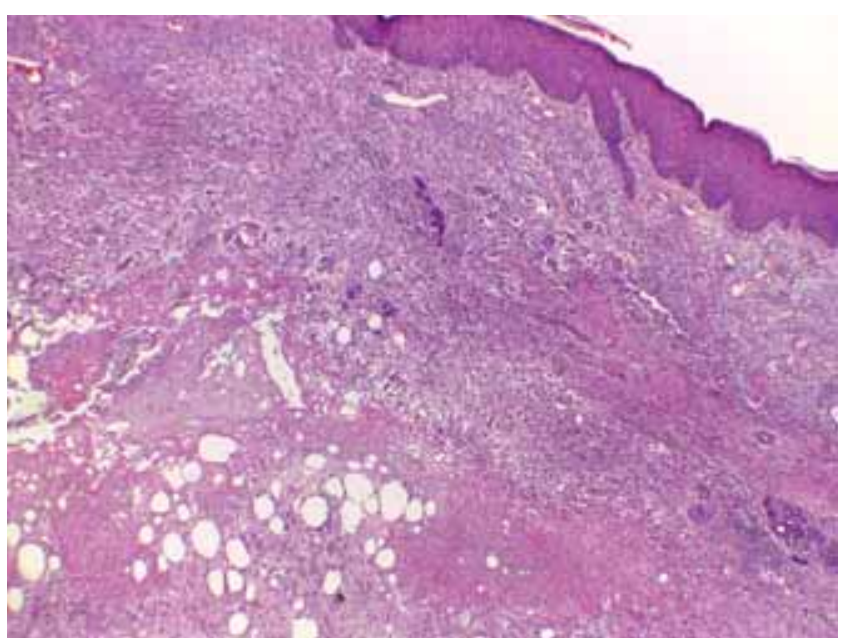

Figure 2: Histopathology (40x). Granulomatous inflammatory infiltrate, with several multinucleated giant cells and areas of necrosis in the deep dermis

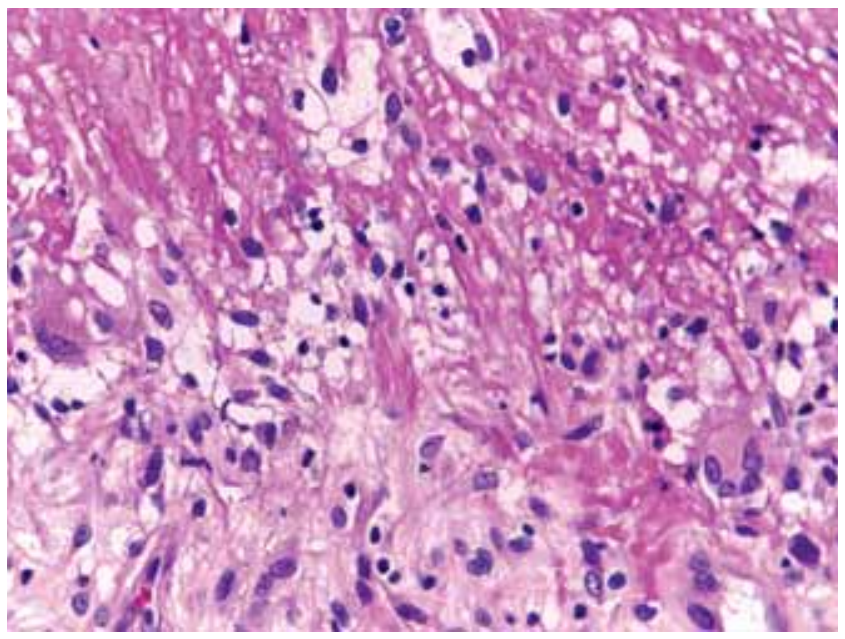

Figure 3: Histopathology (100x). Granulomatous inflammatory infiltrate with xanthomatous histiocytes

invasive procedures and may be resistant to the usual methods of disinfection and sterilization. 1,2,6,7

There are several reports of outbreaks caused by NTM after surgeries. In Brazil, we highlight the outbreaks that occurred in São Paulo (2003-2004), Pará (2004), Rio de Janeiro (2006) and Espírito Santo (2007). Flaws in the techniques of disinfection and sterilization of materials were detected. 7,8 Graph 1 shows the distribution of reported cases of infection by RGM from 1998-2009 in Brazil. We can see that cases were more prevalent in theyears 2006-2008. During this period, there were 13 cases of $\mathrm{M}$. chelonae. The mean age of patients was 51 years, $100 \%$ of them were female, and cosmetic injection to the face was the most common procedure. ${ }^{9}$

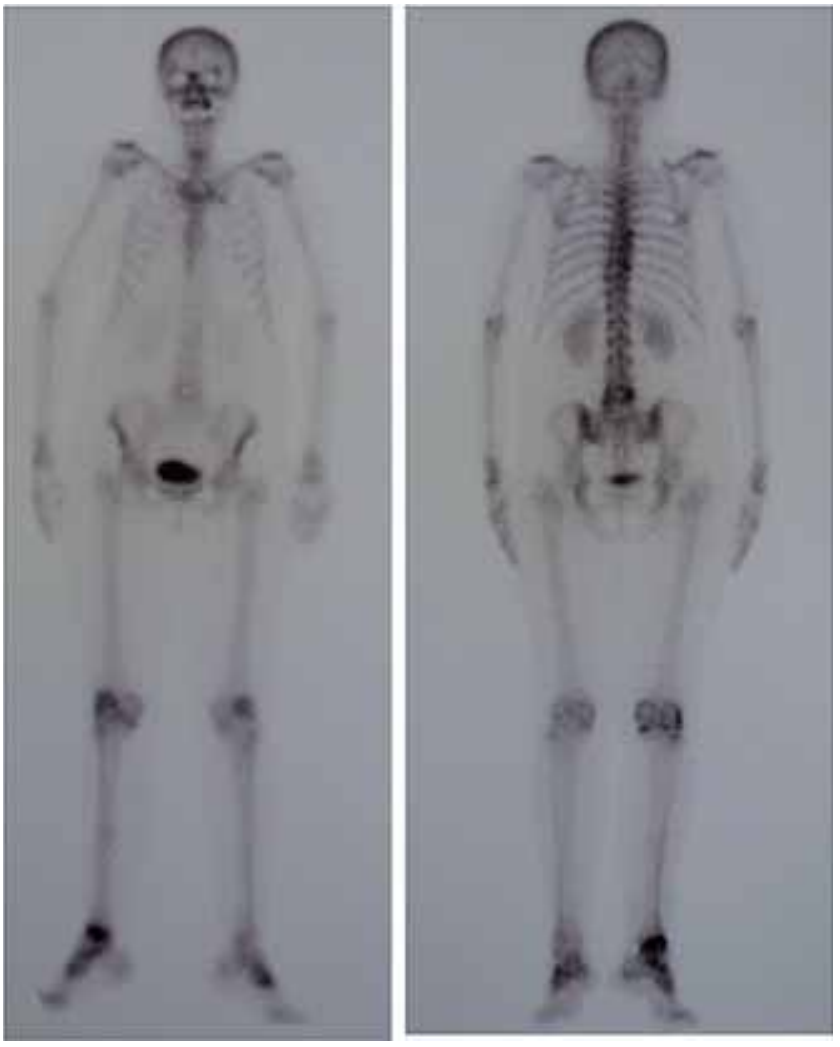

Figure 4: Three-phase bone scintigraphy. Moderate focal hyperconcentration in T7, T9 and L5. Mild hyperconcentration in T4, T5 and S1. Marked diffuse hyperconcentration in the right ankle. Moderate diffuse hyperconcentration in the right knee and tarsal bones. Mild diffuse hyperconcentration in the shoulders, thoracic and lumbar vertebrae, and left knee

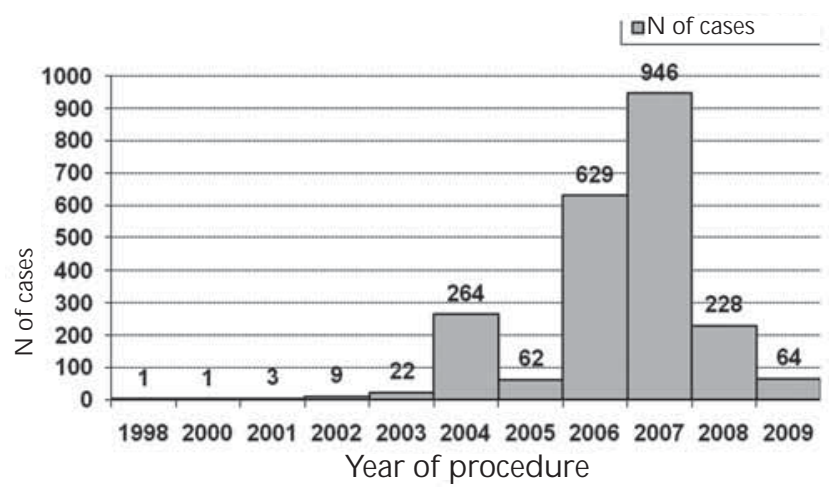

Graph 1: Cases reported from invasive procedures. Distribution of reported cases of infection by rapidly growing mycobacteria associated with invasive procedures, according to the year of the procedure. Brazil, 1998-2009 
NTM occur in the presence or absence of immunosuppression, although they are more frequent in the first situation. 5 The clinical form depends on the immune state of the host, on the type of mycobacterium and on the entry points. In immunocompetent individuals, the infection is usually localized, with one or multiple entry points, such as in acupuncture, mesotherapy and tattoos. In immunocompromised individuals, the infection is usually widespread. ${ }^{2}$

The vascular procedure performed 40 days before the onset of lesions may be considered the possible transmission path. This incubation period is expected, according to the literature. ${ }^{5}$ Although the patient was immunocompetent, she had wiedespread skin infection. A hypothesis to explain this would be the manipulation of initial lesions by the patient and implantation of the agent in other body sites.

The most common clinical presentation - at the site of inoculation - are painless, fistulized nodules and abscesses. These are not accompanied by poor general condition or involvement of internal organs. ${ }^{1,2,3,7}$ Bone scintigraphy revealed arthritis and inflammatory foci.
Previous radiographs showed signs of arthrosis. A hypothesis would be prior joint disease exacerbated by superimposed reactive arthritis, which led to a thorough investigation of diseases such as rheumatoid arthritis and systemic lupus erythematosus.

The diagnosis is based on the histopathology findings and, essentially, on the culture of skin materials. Smear microscopy is usually negative. ${ }^{1,3}$ Species identification is important because it guides laboratory analysis and demonstrates the antimicrobial susceptibility profiles. ${ }^{7}$

Smear microscopy can be performed by Ziehl-Neelsen stain. A disadvantage of this method is that it does not morphologically differentiate between species. Species identification is done by phenotypic and/ or molecular methods. ${ }^{5}$

Cultures can be made in several media, such as thioglycolate broth, blood agar, chocolate agar, MacConkey agar and Lowenstein-Jensen medium. The latter is specific for mycobacteria. ${ }^{7}$ In addition to performing antimicrobial assays, they allow the identification of species by DNA sequencing. ${ }^{10}$

Chart 1: Treatment. Antimicrobial schemes proposed according to the site of the lesions, and the extent and severity of involvement

\section{Site, extent, severity}

Single lesion limited to the skin and subcutaneous tissue*

Multiple lesions limited to the skin and subcutaneous tissue* $^{*}$

Deep wound infection involving the fascia and muscle, intra-peritoneal involvement or evidence of spread, and in cases of arthritis or osteomyelitis, or patients with greater severity of illness

\section{Proposed antimicrobial schemes}

Clarithromycin $500 \mathrm{mg}$ twice daily PO for 6 months

- Include 2 antimicrobials:

1. Clarithromycin $500 \mathrm{mg}$ twice daily PO for at least 6 months;

2. $15 \mathrm{mg} / \mathrm{kg}$ up to $1 \mathrm{~g} /$ dose once daily IM or IV for 1 week, beginning intraoperatively after collecting material for microbiological examination. Then 3 times weekly for 1-2 months**.

- Include 3 antimicrobials:

1. Clarithromycin $500 \mathrm{mg}$ twice daily IV

2. Amikacin: $15 \mathrm{mg} / \mathrm{kg}$ up to $1 \mathrm{~g} /$ dose once daily IM or IV for 2 weeks, beginning immediately after surgical debridement. Then 3 times weekly for 1-2 months**.

3. Imipenem (500 mg four times daily IV) for 3-8 weeks.

* absence of prosthesis or other foreign body.

** The use of amikacin may be extended for up to six months, according to the progress of the case and the physician's discretion.

NOTE: M. chelonae is the only species to which monotherapy with clarithromycin can be implemented without surgical debridement.

PO: orally; IV: intravenous; IM: intramuscular

Source: Brasil, 2009. ${ }^{10}$ 
PCR is a sensitive and specific molecular method that has been used for detection of mycobacteria. Multiplex PCR enables the detection of multiple DNA sequences in a single reaction, with greater speed and specificity. ${ }^{5}$ For the identification of RGM, the rpoB gene should be used, whereas for the identification of slow-growing mycobacteria the hsp65 gene should be employed. ${ }^{10}$
Treatment is not standardized. Two or three antimicrobials may be associated according to the antibiogram. Regimens with clarithromycin used continuously for four to six months have been encouraged. ${ }^{2}$ Combination therapy with other antibiotics is preferable in order to prevent resistance. ${ }^{5,10}$ Chart 1 shows several antimicrobial schemes suggested according to the site of the lesions, extent of involvement and presence of comorbidities. ${ }^{10}$

We highlight the importance of investigating atypical mycobacteriosis when faced with granulomatous lesions associated with a history of invasive procedures.

\section{REFERENCES}

1. Sampaio SAP, Rivitti EA. Dermatologia. 3. ed. São Paulo: Artes Médicas; 2007.

2. Olivares L, Fandiño M, Pardal PF, Cortiñas MEP, Maronna E. Infección cutánea por Mycobacterium chelonae. Dermatol. Argent. 2011;17:446-50.

3. Chichotky Y, Cañete G, Velasco Zamora JL, Velasco Zamora J. Cuando lo típico es también atípico: vasculitis asociada a infección cutánea por micobacteria atípica. AR Artritis Reumatoidea 2010;1:26-30.

4. Ferreira 0, Duarte AF, Baudrier T, Mota A, Simões JS, Azevedo F. A cutaneous infection by Mycobacterium chelonae in a patient with rheumatoid arthritis. Dermatol Online J. 2010;16:3.

5. Poroca Dda R, Lima AS, Lima JF, Cruz HL, Montenegro Rde A, Melo FL, et al. Differentiation of micobacteria by multiplex PCR. Rev Soc Bras Med Trop. 2009;42:716-22

6. Fontana RT. The Mycobacterias of Rapid Growth and the hospital infection: a public health problem. Rev Bras Enferm. 2008:61:371-6.

7. Macedo JLS, Maierovitch C, Henriques P. Infecções pós-operatórias por micobactérias de crescimento rápido no Brasil. Rev Bras Cir Plást. 2009;24:544-51.

8. Macadam SA, Mehling BM, Fanning A, Dufton JA, Kowalewska-Grochowska KT, Lennox P, et al. Nontuberculous Mycobacterial Breast Implant Infections. Plast Reconstr Surg. 2007;119:337-44.

9. Brasil. Agência Nacional de Vigilância Sanitária (Anvisa). Relatório descrito de investigação de casos de infecções por micobactérias não tuberculosas de crescimento rápido (MCR) no Brasil no período de 1998 a 2009. Brasília: Anvisa; 2011.

10. Brasil. Agência Nacional de Vigilância Sanitária (Anvisa). Ministério da Saúde. Secretaria de Vigilância em Saúde. Nota técnica conjunta n 1/2009 - Svs/Ms e Anvisa. Infecções por micobactérias de crescimento rápido: fluxo de notificações, diagnósticos clínico, microbiológico e tratamento. Brasília: Anvisa; 2009.
M AILING ADDRESS:

$\mathrm{N}$ athalia Dias $\mathrm{N}$ egrão $\mathrm{M}$ urback

A v. Felinto M uller, 1, 79000-000 - Campo Grande - M S

Brazil

E-mail: nmurback@yahoo.com.br

How to cite this article: Murback NDN, Higa Júnior MG, Pompílio MA, Cury ESJ, Hans Filho G, Takita LC. Disseminated cutaneous atypical mycobacteriosis by $\mathrm{M}$. chelonae after sclerotherapy of varicose veins in a immunocompetent patient: a case report . An Bras Dermatol. 2015;90 (3 Suppl 1):S138-42. 